\title{
Prognostic significance of CD44V6 expression in osteosarcoma: a meta-analysis
}

\author{
Yunyuan Zhang ${ }^{1 *}$, Chunming Ding ${ }^{2}$, Jing Wang ${ }^{3,4}$, Guirong Sun ${ }^{1}$, Yongxian Cao ${ }^{1}$, Longqiang Xu' ${ }^{1}$ Lan Zhou ${ }^{3}$ \\ and Xian Chen ${ }^{1 *}$
}

\begin{abstract}
Numerous individual studies evaluating the relationship between CD44V6 over-expression and prognostic impact in patients with osteosarcoma (OS) have yielded in conclusive results. This meta-analysis aimed to determine the value of cell adhesion molecule CD44V6 in prognosis of OS by conducting a systematic review and meta-analysis. A comprehensive search was conducted using PubMed (medline), Embase, ISI Web of Knowledge, Springer, the Cochrane Library, Scopus, BioMed Central, ScienceDirect, Wanfang, Weipu, and China National Knowledge Internet (CNKI) databases from inception through May 26, 2015. All available articles written in English or Chinese that investigated the expression of CD44V6 and the prognosis of OS were included. The quantity of the studies was evaluated according to the critical review checklist of the Dutch Cochrane Centre proposed by MOOSE. Finally, a total of eight studies with 486 OS patients were involved and the results indicated that the positive expression of CD44V6 predicts neoplasm metastasis ( $R R=1.76,95 \% \mathrm{Cl} 1.38-2.25, p<0.00001)$, and poor survival in OS with the pooled HR of 1.53 (95\% Cl 1.25-1.88, $p<0.0001$ ). No significant heterogeneity was observed among all studies. In conclusion, the present meta-analysis and systematic review strongly suggest that CD44V6 over-expression is associated with overall survival rate and metastasis in OS, and may be used as a prognostic biomarker to guide the clinical therapy for OS.
\end{abstract}

Keywords: CD44V6, Osteosarcoma, Prognosis, Meta-analysis

\section{Introduction}

Osteosarcoma (OS) is the most common malignancy originating from the bone that mainly afflicts the pediatric age group and young adults $[1,2]$. It is the second leading cause of cancer-related death in adolescents due to the fact that most of the patients involve in fatal metastasis. It is approximately $20-25 \%$ of newly diagnosed patients have detectable lung-related metastasis $[3,4]$. Despite recent improvement in surgical, radiotherapy and neoadjuvant chemotherapy, the long-term survival of patients with OS is still less than $50 \%$ [5]. At present, the ability to predict the prognosis and metastasis of OS is limited because the mechanism of oncogenetic is still not fully elucidated. So far, the clinical prognostic

\footnotetext{
* Correspondence: hellozyycool@163.com; cxkakicoco2014@163.com ${ }^{1}$ Department of Clinical Laboratory, The Affiliated Hospital of Qingdao University, Qingdao 266003, China

Full list of author information is available at the end of the article
}

factors were still demographics (age and sex), site, stage, tumor size, and the response to chemotherapy. Therefore, identifying prognostic markers in OS could be informative for selecting proper management. In recent years, the expression of CD44 variant isoform V6 (CD44V6) has been identified as one of the potential prognostic and metastatic biomarkers for OS.

Biomarkers are used as tools in cancer prognosis and metastasis [6]. CD44 is a kind of trans-membrane glycoprotein and the structure contains seven extracellular domains, a trans-membrane domain, and a cytoplasmic domain [7]. Due to the alternative splicing of CD44, at least 10 variants are generated during transcription [8]. CD44V6 is one of the variant isoforms $(\mathrm{CD} 44 \mathrm{~V})$, which has been reported to regulate the extracellular matrix, promote cell motility, and suppress tumor apoptosis [9-12]. In fact, CD44V6 has been implicated in promoting tumor progression [13]. There are increased levels of CD44V6, 
which could serve as a prognostic marker in various solid tumors, including myxofibrosarcoma [14], gastric cancer [15], colorectal cancer [16], non-small-cell lung cancer [17], esophageal squamous cell carcinoma, [18] and hepatocellular carcinoma [19].

Many published data suggested that over-expression of CD44V6 was associated with high risk of tumor metastasis and worse survival in patients with OS. However, some other studies showed controversial results and no consensus had been reached. To investigate the relationship between the potential biomarker and the clinical outcome, we conducted a meta-analysis of all available studies relating CD44V6 expression with patients in OS.

\section{Methods}

\section{Search strategy and selection criteria}

The PubMed (medline), Embase, ISI Web of Knowledge, Springer, the Cochrane Library, Scopus, BioMed Central, ScienceDirect, Wanfang, Weipu, and China National Knowledge Internet (CNKI) databases were used to conduct a comprehensive search for studies that evaluated the accuracy of CD44V6 for the metastasis and prognosis of OS. In addition to the electronic databases which published between inception and May 26, 2015, we also searched the reference list of each primary study and of previous systematic reviews. The search strategy included the following keywords variably combined by "CD44V6", "CD44 variation 6" "osteosarcoma", and "bone tumor".

The present meta-analysis was conducted totally following the guidelines of preferred reporting items for meta-analysis of observational studies in epidemiology group (MOOSE) and MOOSE checklist for our study is shown in Additional file 1: Table S1.

\section{Inclusion and exclusion criteria}

Inclusion criteria: (1) measurement of CD44V6 in OS using commercial reagents; (2) pathological diagnosis (gold standard) confirmed for newly diagnosed patients with OS; (3) the studies had to provide sufficient information to construct the $2 \times 2$ contingency table; and (4) publications written in English or Chinese.

Exclusion criteria: (1) OS diagnosed without a biopsy and there was no clear cut-off value in the literature; (2) similar studies from the same author as well as multiple duplicate data in the different works, excluding earlier and smaller sample data; (3) animal experiments, reviews, correspondences, case reports, talks, letters, expert opinions, and editorials without original data; and (4) studies of non dichotomous CD44V6 expression levels and absence of survival outcome were excluded.

\section{Quality assessment}

The included studies were evaluated according to the critical review checklist of the Dutch Cochrane Centre proposed by MOOSE [20]. The key points were as following: (I) enough information of the carcinoma, (II) clear description of outcome assessment, (III) clear description of study design, (IV) clear description of CD44V6 measurement, (V) clear description of cut-off of CD44V6, and (VI) sufficient period of follow-up. The studies without mentioning all these points were excluded.

\section{Data extraction}

Two investigators (YYZ and $\mathrm{XC}$ ) evaluated the eligibility of all retrieved studies and extracted the relevant data independently. Extracted databases were then crosschecked between the two authors to rule out any discrepancy. Data regarding the following for each included studies were extracted independently: first authors' surname, publication year, CD44V6 assessment methods, and the cut-off definition. Corresponding authors were contacted if further information was needed. The study was excluded if no response was received after sending a reminder.

\section{Statistical analysis}

The statistical analysis was carried out using the Review Manager (RevMan) software version 5.3 (The Nordic Cochrane Centre, The Cochrane Collaboration, Copenhagen, Denmark) and STATA 12. All these hazard ratios and $95 \%$ confidence interval $(\mathrm{CI})$ were calculated. Pooled HR was calculated using a fixed-effects model or random-effects model to evaluate the relationship between CD44V6 expression and metastasis or overall survival. $\mathrm{I}^{2}$ statistics were used to evaluate the between-study heterogeneity analysis in this study. The fixed-effects model was used when there was no significant heterogeneity between the included studies $\left(\mathrm{I}^{2}<30 \%\right)$. Sensitivity analysis was used to shows influence by any individual study. Publication bias was estimated using a funnel plot with a Begg's linear aggression test; funnel plot asymmetry on the natural logarithm scale of the HR was measured by a linear regression.

\section{Results \\ Eligible studies}

The initial search retrieved a total of 764 references that related to the metastasis or prognosis of CD44V6 in OS. After duplicated data removed, 648 articles were left. After screening titles and abstracts of identified articles, 626 articles were excluded because they were not related to the current study according to the exclusion criteria. Upon a further full text review, we excluded another 14, and 8 studies were included in our study [21-28] (Fig. 1). 


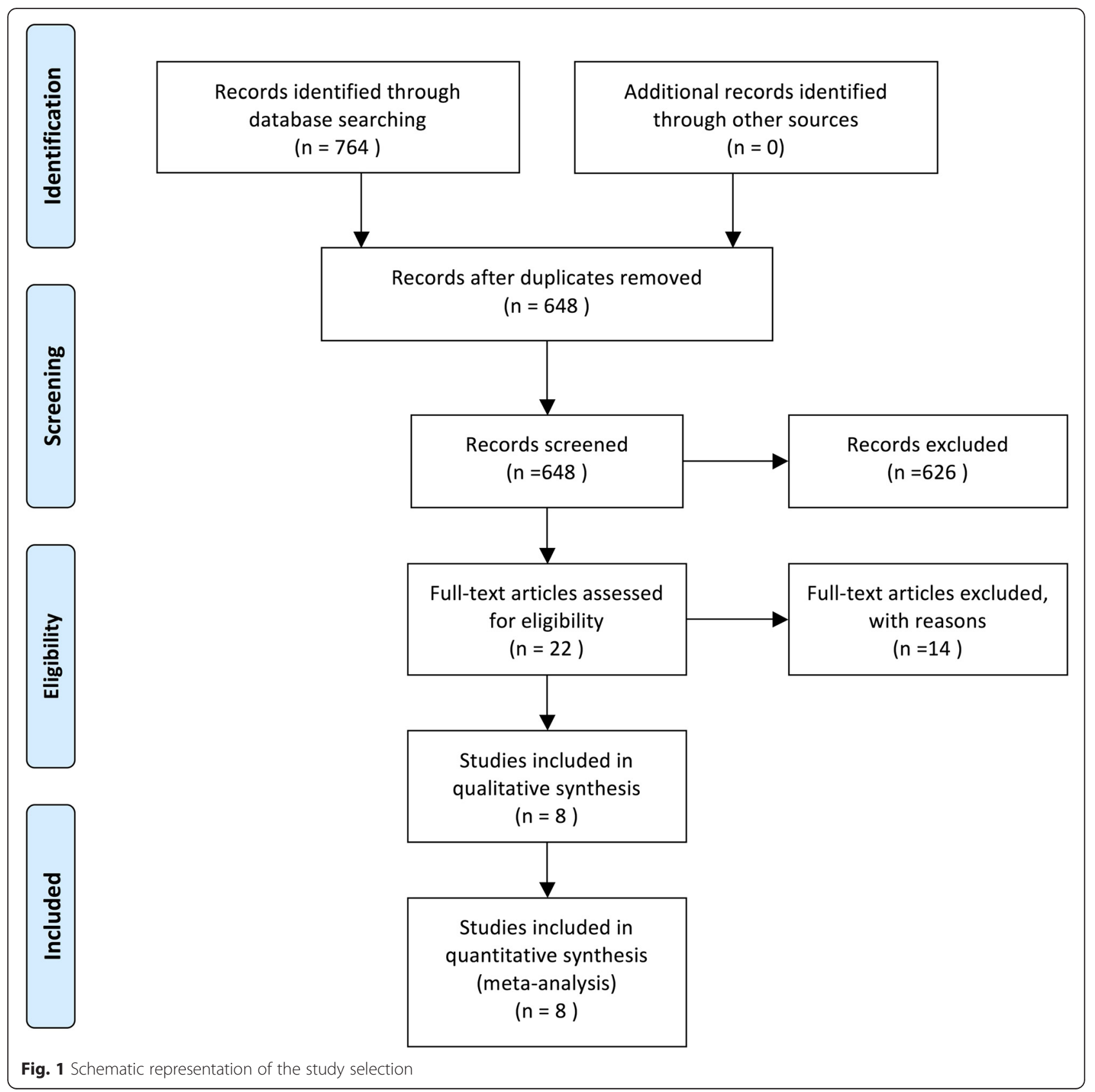

Table 1 Characteristics of studies included in the metastasis meta-analysis

\begin{tabular}{|c|c|c|c|c|c|c|c|c|c|c|}
\hline \multirow[t]{2}{*}{ Study } & \multirow[t]{2}{*}{ Year } & \multirow{2}{*}{$\begin{array}{l}\text { Age } \\
\text { (median) }\end{array}$} & \multirow[t]{2}{*}{ Assay kit } & \multirow{2}{*}{$\begin{array}{l}\text { No. of } \\
\text { patients }\end{array}$} & \multirow[t]{2}{*}{ Method } & \multirow{2}{*}{$\begin{array}{l}\text { CD44V66 } \\
\text { cut-off }\end{array}$} & \multicolumn{2}{|c|}{ CD44V6 positive } & \multicolumn{2}{|c|}{ CD44V6 negative } \\
\hline & & & & & & & Metastasis & Total & Metastasis & Total \\
\hline Deng et al. & 2013 & 18.3 & ZSGB-BIO & 90 & $\mathrm{IHC}$ & $>6$ score & 38 & 59 & 12 & 31 \\
\hline Guo et al. & 2007 & 18.6 & ZSGB-BIO & 49 & $\mathrm{IHC}$ & $>5 \%$ & 16 & 27 & 5 & 22 \\
\hline Hu et al. & 2009 & 19 & Santa Cruz & 87 & $\mathrm{IHC}$ & $>3$ score & 25 & 45 & 12 & 42 \\
\hline Kim et al. & 2002 & 17 & Zymed & 50 & $\mathrm{IHC}$ & $>50 \%$ & 4 & 26 & 6 & 24 \\
\hline Kuryu et al. & 1999 & 19 & $R \& D$ & 39 & $\mathrm{IHC}$ & $>10 \%$ & 13 & 18 & 10 & 21 \\
\hline Li et al. & 2008 & 23.3 & Maixin & 35 & $\mathrm{IHC}$ & $>0 \%$ & 14 & 19 & 3 & 16 \\
\hline Zhu et al. & 2014 & 25 & ZSGB-BIO & 66 & $\mathrm{IHC}$ & $>1$ score & 39 & 56 & 5 & 10 \\
\hline
\end{tabular}


Table 2 Characteristics of studies included in the 5-year survival meta-analysis

\begin{tabular}{|c|c|c|c|c|c|c|c|c|c|c|}
\hline \multirow[t]{2}{*}{ Study } & \multirow[t]{2}{*}{ Year } & \multirow{2}{*}{$\begin{array}{l}\text { Age } \\
\text { (median) }\end{array}$} & \multirow[t]{2}{*}{ Assay kit } & \multirow{2}{*}{$\begin{array}{l}\text { No. of } \\
\text { patients }\end{array}$} & \multirow[t]{2}{*}{ Method } & \multirow{2}{*}{$\begin{array}{l}\text { CD44V6 } \\
\text { cut-off }\end{array}$} & \multicolumn{2}{|c|}{ CD44V6 positive } & \multicolumn{2}{|c|}{ CD44V6 negative } \\
\hline & & & & & & & Metastasis & Total & Metastasis & Total \\
\hline Deng et al. & 2013 & 18.3 & ZSGB-BIO & 90 & $\mathrm{HC}$ & $>6$ score & 56 & 59 & 20 & 31 \\
\hline Kuryu et al. & 1999 & 19 & $R \& D$ & 39 & $\mathrm{IHC}$ & $>10 \%$ & 14 & 18 & 9 & 21 \\
\hline Lin et al. & 2002 & 22 & Maixin & 70 & $\mathrm{IHC}$ & $>2$ score & 58 & 64 & 4 & 6 \\
\hline Zhu et al. & 2014 & 25 & ZSGB-BIO & 66 & $\mathrm{HC}$ & $>1$ score & 53 & 56 & 6 & 10 \\
\hline
\end{tabular}

The main characteristics of the included studies were summarized in Tables 1 and 2. In summary, immunohistochemistry (IHC) was used for all studies to determine the expression of CD44V6. The results were judged by cut-off in two ways: percentage of positivity and immunoreactivity (intensity) score (IRS).

\section{Meta-analysis}

The intensity of relationship between the expression levels of CD44V6 and overall survival or metastasis were described as hazard ratios (HRs). For studies evaluating the overall survival and metastasis, STATA 12 and RevMan 5.3 showed there was no significant between-study heterogeneity among those studies for the overall survival of CD44V6 ( $\left.\mathrm{I}^{2}<30 \%\right)$, so the fixed-effect model was used to determine the pooled HR with corresponding 95 \% CI. As shown in Figs. 2 and 3, the combined $\mathrm{HR}$ for all eligible studies evaluating CD44V6 overexpression on overall 5-years disease-free survival and metastasis was 1.53 (95\% CI 1.25-1.88, $p<0.0001, \mathrm{I}^{2}=$ $0 \%$ ) and 1.76 (95\% CI 1.38-2.25, $p<0.00001, \mathrm{I}^{2}=$ $18 \%)$, respectively. Sensitivity analysis was used to evaluate the stability of results. No matter which study removed, the heterogeneity does not change significantly, suggesting that the results of our analysis do not overly rely on one study and the conclusions are stable. These results suggest that CD44V6 over-expression was an indicator of poor prognosis and metastasis for OS patients.

\section{Publication bias}

Funnel plot with Revman was used to evaluate the publication bias of the literatures. The shape of the funnel plot did not reveal any evidence of obvious asymmetry (Figures not shown).

To validate the result, we also performed a Begg's funnel plot with STATA, and no publication bias was found of both metastasis and prognosis in OS $(z=0.00$; $p>0.05)$.

\section{Discussion}

OS is a life threatening primary bone neoplasm that often occurs in teenagers. Disease free survival escalated from $<20 \%$ prior to the introduction of effective chemotherapy to around $60 \%$ and overall survival to $60-70 \%$ [29]. With 20-25 \% having detectable metastases at diagnosis, OS is characterized by a high propensity for metastasis, mostly to the lungs. The overall survival rate decreases to $30 \%$ when metastasis is detected at the time of diagnosis. Despite early detection screening protocols, improved surgical techniques, advanced radio, and chemotherapeutic regimens, limited improvements to predict the prognosis of OS patients have been achieved over the past 20 years. Therefore, the update of early prognostic biomarkers is urgently needed to adapt the proper therapy to the malignancy. Many researchers have reported that high expression of certain cell surface markers indicates bad clinical features and poor prognosis, and CD44V6 is one of the potential prognostic markers for OS.

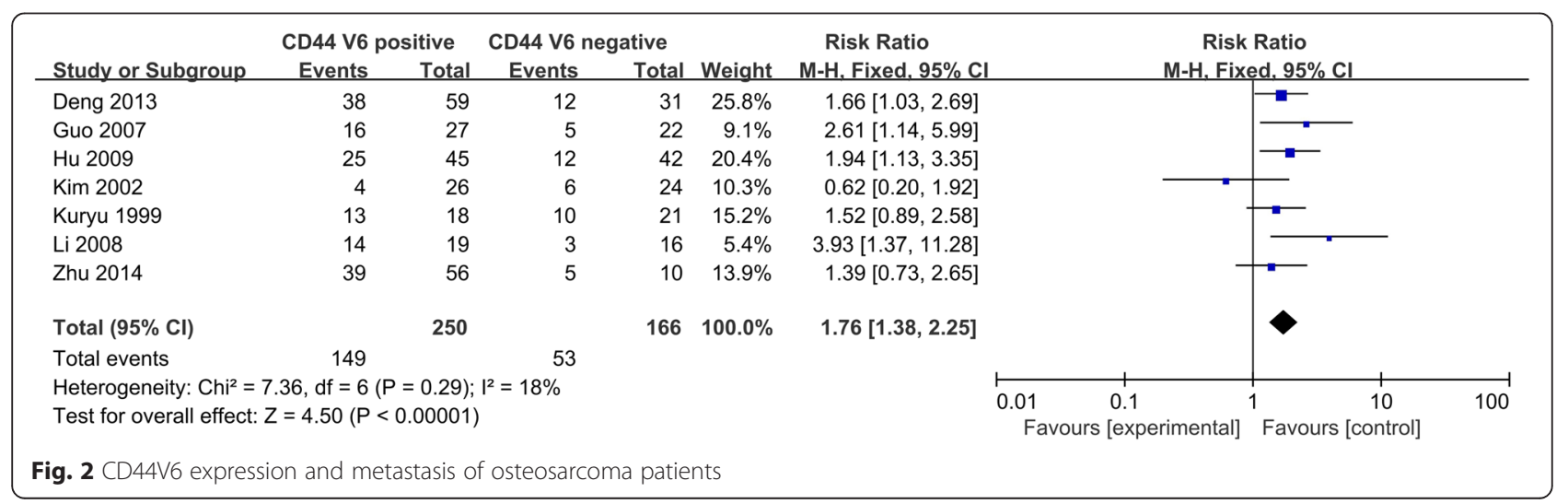




\begin{tabular}{|c|c|c|c|c|c|c|c|c|c|}
\hline \multirow[b]{2}{*}{ Study or Subgroup } & \multicolumn{2}{|c|}{ CD44 V6 positive } & \multicolumn{2}{|c|}{ CD44 V6 negative } & & \multirow{2}{*}{$\begin{array}{l}\text { Risk Ratio } \\
\text { M-H, Fixed, } 95 \% \mathrm{Cl}\end{array}$} & \multirow{2}{*}{\multicolumn{3}{|c|}{$\begin{array}{c}\text { Risk Ratio } \\
\text { M-H. Fixed. } 95 \% \mathrm{Cl}\end{array}$}} \\
\hline & Events & Total & Events & Total & Weight & & & & \\
\hline Deng 2013 & 56 & 59 & 20 & 31 & $50.4 \%$ & $1.47[1.13,1.92]$ & & $\mathbf{E}$ & \\
\hline Kuryu 1999 & 14 & 18 & 9 & 21 & $16.0 \%$ & $1.81[1.04,3.15]$ & & $\rightarrow$ & \\
\hline Lin 2002 & 58 & 64 & 4 & 6 & $14.1 \%$ & $1.36[0.77,2.41]$ & & 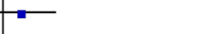 & \\
\hline Zhu 2014 & 53 & 56 & 6 & 10 & $19.6 \%$ & $1.58[0.95,2.63]$ & & - & \\
\hline Total $(95 \% \mathrm{Cl})$ & & 197 & & 68 & $100.0 \%$ & $1.53[1.25,1.88]$ & & $\bullet$ & \\
\hline Total events & 181 & & 39 & & & & & & \\
\hline $\begin{array}{l}\text { Heterogeneity: } \mathrm{Chi}^{2}= \\
\text { Test for overall effect: }\end{array}$ & $\begin{array}{l}63, \mathrm{df}=3 \\
=4.04(\mathrm{P}\end{array}$ & $\begin{array}{l}=0.89) ; 1 \\
0001)\end{array}$ & $1^{2}=0 \%$ & & & & $\begin{array}{lll}0.01 & 0.1 & 1 \\
& \text { Favours [experimental] }\end{array}$ & $\begin{array}{l}1 \\
\text { Favours [control] }\end{array}$ & 100 \\
\hline
\end{tabular}

CD44 is a trans-membrane glycoprotein, and some variant isoforms of CD44 are reportedly associated with increased invasion, metastasis, and poor prognosis [30], particularly the CD44V6 [13]. CD44V6 promoting the metastasis of cancer has been documented and the mechanism may be attributed to its interactions with various components of the extracellular matrix. Several published data have suggested that CD44V6 expression is related to metastatic potential, prognosis, and the biologic properties of human malignancies. CD44V6 was found in $69 \%$ of prostate cancer cases [31], $26 \%$ of non-Hodgkin's lymphomas cases [32], $13 \%$ of ovarian cancer cases [33], $55 \%$ of cervical cancer [34], and $46 \%$ of OS [35]. There are also studies showing that the presence of CD44V6 participated in the MAPK and the PI3K/Akt signaling pathways [36, 37]. Nakajima et al. suggested that CD44V6 could be an onco-protein in the bone tissue, which could be expressed in the metastasized OS [38]. The prognostic value of CD44V6 for patients with cancer has also been studied in various solid tumors. To our knowledge, no systematic meta-analysis in evaluating the prognostic values of CD44V6 and OS has been published.

Eight publications including 486 patients have been combined in the present meta-analysis, indicating a statistically significant role of CD44V6 on overall survival $(\mathrm{HR}=1.53,95 \%$ CI 1.25-1.88, $p<0.0001)$ and metastasis $(R R=1.76,95 \%$ CI 1.38-2.25, $p<0.00001)$ in patients with OS. As a well-established, widely accepted method in medical science, immunohistochemistry (IHC) was used in all these inclusion data. We suggest that IHC should be adapted to determine the expression of CD44V6 from biopsy tissue. Our meta-analysis has its limitations and there are several issues should be considered. First, although there is no publication bias, potential publication bias may still exist. Studies with desirable results might be published more easily, which can lead to an over-estimation of overall accuracy. Second, only the studies that were published in English or Chinese were included in this meta-analysis, which could affect our results. Finally, since the rarity of primary malignant tumors of the bone, accounting for less than $0.2 \%$ of all cancers [39], the number of included studies in this meta-analysis was only eight. It might weaken the reliability of our results. To strengthen our findings, well-designed clinical studies with larger sample size should be carried out in the future before the application of CD44V6 on the metastasis and prognosis of OS patients. Even the inherent limitations of metaanalysis is existed, this study represents a quantified synthesis of published studies and emphasizes more attention about new prognostic biomarkers on OS.

\section{Conclusion}

In conclusion, this meta-analysis suggests that CD44V6 over-expression is associated with overall survival rate and metastasis in osteosarcoma, and may be used as a prognostic biomarker to guide the clinical therapy for osteosarcoma.

\section{Additional file}

Additional file 1: Table S1. Presents the completed MOOSE checklist for the meta-analysis. (DOC $58 \mathrm{~kb}$ )

Competing interests

The authors declare that they have no competing interests.

Authors' contributions

$X C$ and $Y Y Z$ conceived and designed the experiments. $X C, J W, Y Y Z$ performed the experiments. ZC, CMD, JW, GRS, YXC, LQX, JZ, LZ, and YYZ analyzed the data. JW contributed reagents/materials/analysis tools. XC, LZ, and $Y Y Z$ wrote the paper. All authors read and approved the final manuscript.

\section{Acknowledgements}

This research was fully supported by the grants from the National Natural Science Foundation of China (No. 81501872) and the Shangdong Young Scientists Award Foundation (No. BS2014YY034).

\section{Author details}

${ }^{1}$ Department of Clinical Laboratory, The Affiliated Hospital of Qingdao University, Qingdao 266003, China. ${ }^{2}$ Department of Orthopaedics, Qingdao Municipal Hospital, Qingdao 266071, China. ${ }^{3}$ College of Laboratory Medicine, Key Laboratory of Laboratory Medical Diagnostics designated by Chinese Ministry of Education, Chongqing Medical University, Chongqing 400016, China. ${ }^{4}$ Molecular Oncology Laboratory, Department of Orthopaedic Surgery, The University of Chicago Medical Center, Chicago, IL 60637, USA. 
Received: 15 July 2015 Accepted: 26 November 2015

Published online: 23 December 2015

\section{References}

1. Siclari VA, Qin L. Targeting the osteosarcoma cancer stem cell. J Orthop Surg Res. 2010;5:78.

2. Picci P, Mercuri M, Ferrari S, Alberghini M, Briccoli A, Ferrari C, et al. Surviva in high-grade osteosarcoma: improvement over 21 years at a single institution. Ann Oncol. 2010;21:1366-73.

3. Ta HT, Dass CR, Choong PF, Dunstan DE. Osteosarcoma treatment: state of the art. Cancer Metastasis Rev. 2009;28:247-63.

4. Roy R, Yang J, Moses MA. Matrix metalloproteinases as novel biomarkers and potential therapeutic targets in human cancer. J Clin Oncol. 2009;27:5287-97.

5. Bruland OS, Pihl A. On the current management of osteosarcoma. A critical evaluation and a proposal for a modified treatment strategy. Eur J Cancer. 1997;33:1725-31.

6. Wibulswas A, Croft D, Pitsillides AA, Bacarese-Hamilton I, Mclntyre P, Genot E, et al. Influence of epitopes CD44v3 and CD44v6 in the invasive behavio of fibroblast-like synoviocytes derived from rheumatoid arthritic joints. Arthritis Rheum. 2002;46:2059-64

7. Arch R, Wirth K, Hofmann M, Ponta H, Matzku S, Herrlich P, et al. Participation in normal immune responses of a metastasis-inducing splice variant of CD44. Science. 1992;257:682-5.

8. Jalkanen ST, Bargatze RF, Herron LR, Butcher EC. A lymphoid cell surface glycoprotein involved in endothelial cell recognition and lymphocyte homing in man. Eur J Immunol. 1986;16:1195-202.

9. Isacke CM, Sauvage CA, Hyman R, Lesley J, Schulte R, Trowbridge IS. Identification and characterization of the human Pgp-1 glycoprotein. Immunogenetics. 1986;23:326-32.

10. Lucas MG, Green AM, Telen MJ. Characterization of the serum In(Lu)-related antigen: identification of a serum protein related to erythrocyte p80. Blood. 1989:73:596-600.

11. Picker $L J$, Nakache M, Butcher EC. Monoclonal antibodies to human lymphocyte homing receptors define a novel class of adhesion molecules on diverse cell types. J Cell Biol. 1989;109:927-37.

12. Jung T, Gross W, Zoller M. CD44v6 coordinates tumor matrix-triggered motility and apoptosis resistance. J Biol Chem. 2011;286:15862-74.

13. Matuschek C, Lehnhardt M, Gerber PA, Poremba C, Hamilton J, Lammering $G$, et al. Increased CD44s and decreased CD44v6 RNA expression are associated with better survival in myxofibrosarcoma patients: a pilot study. Eur J Med Res. 2014;19:6

14. Chen Y, Fu Z, Xu S, Xu Y, Xu P. The prognostic value of CD44 expression in gastric cancer: a meta-analysis. Biomed Pharmacother. 2014;68:693-7.

15. Chen L, Jiang B, Wang Z, Liu M, Yang H, Xing J, et al. Combined preoperative CEA and CD44v6 improves prognostic value in patients with stage I and stage II colorectal cancer. Clin Transl Oncol. 2014;16:285-92.

16. Zhao S, He JL, Qiu ZX, Chen NY, Luo Z, Chen BJ, et al. Prognostic value of CD44 variant exon 6 expression in non-small cell lung cancer: a metaanalysis. Asian Pac J Cancer Prev. 2014;15:6761-6.

17. Yang H, Liu J, Yu H, Sun P, Hu Y, Zhong J, et al. Expression and association of CD44v6 with prognosis in T2-3N0M0 esophageal squamous cell carcinoma. J Thorac Dis. 2014;6:91-8.

18. Zhou ZJ, Dai Z, Zhou SL, Fu XT, Zhao YM, Shi YH, et al. Overexpression of HnRNP A1 promotes tumor invasion through regulating CD44v6 and indicates poor prognosis for hepatocellular carcinoma. Int J Cancer. 2013;132:1080-9.

19. Perabo FG, Frössler C, Landwehrs G, Schmidt DH, von Rücker A, Wirger A, et al. Indirubin-3'-monoxime, a CDK inhibitor induces growth inhibition and apoptosis-independent up-regulation of survivin in transitional cell cancer. Anticancer Res. 2006;26:2129-35.

20. Stroup DF, Berlin JA, Morton SC, Olkin I, Williamson GD, Rennie D, et al. Meta-analysis of observational studies in epidemiology: a proposal for reporting. Meta-analysis of observational studies in epidemiology (MOOSE) group. JAMA. 2000;283:2008-12.

21. Kim HS, Park YB, Oh JH, Jeong J, Kim CJ, Lee SH. Expression of CD44 isoforms correlates with the metastatic potential of osteosarcoma. Clin Orthop Relat Res. 2002;184-90.

22. Deng Z, Niu G, Cai L, Wei R, Zhao X. The prognostic significance of CD44V6, $\mathrm{CDH11}$, and beta-catenin expression in patients with osteosarcoma. Biomed Res Int. 2013;13:496193.
23. Kuryu M, Ozaki T, Nishida K, Shibahara M, Kawai A, Inoue H. Expression of CD44 variants in osteosarcoma. J Cancer Res Clin Oncol. 1999:125:646-52.

24. Cheng CL, Dong Z, Min L. The clinical significance of CD44V6 expression in osteosarcoma. Tumor. 2008;128:136-8 (in Chinese).

25. Jiang Z, Fulai C, Yueming C, Lei Z. The significance of CD44V6 and MTA1 in osteosarcoma. J Harbin Medical University. 2014;3:186-90 (in Chinese).

26. Hongzhang G, Shuanke W, Yangzhen O. The expression of CD44V6 in osteosarcoma. Tumor. 2007;127:817-20 (in Chinese).

27. Jianhua L, Lei C, Sheng Z. The clinical significance of CD44V6 and MMPS expression in osteosarcoma. Chinese Journal of Bone Tumor and Bone Disease. 2002;1:35-7 (in Chinese).

28. Hu W, Chen A, Guo F, Li F. The expression and clinical significance of KAl1 and CD44v6 protein in human osteosarcoma. The Chinese-German Journal of Clinical Oncology. 2009;8:232-6.

29. Osborne TS, Khanna C. A review of the association between osteosarcoma metastasis and protein translation. J Comp Pathol. 2012;146:132-42.

30. Bielack $S$, Jürgens $H$, Jundt $G$, Kevric M, Kühne T, Reichardt $P$, et al. Osteosarcoma: the COSS experience. Cancer Treat Res. 2009;152:289-308.

31. Zhang XG, Lu XF, Jiao XM, Chen B, Wu JX. PLK1 gene suppresses cell invasion of undifferentiated thyroid carcinoma through the inhibition of CD44v6, MMP-2 and MMP-9. Exp Ther Med. 2012;4:1005-9.

32. Noordzij MA, van Steenbrugge GJ, Verkaik NS, Schroder FH, van der Kwast $\mathrm{TH}$. The prognostic value of CD44 isoforms in prostate cancer patients treated by radical prostatectomy. Clin Cancer Res. 1997;3:805-15.

33. Terpe HJ, Koopmann R, Imhof BA, Gunthert U. Expression of integrins and CD44 isoforms in non-Hodgkin's lymphomas: CD44 variant isoforms are preferentially expressed in high-grade malignant lymphomas. J Pathol. 1994;174:89-100.

34. Sliutz G, Tempfer C, Winkler S, Kohlberger P, Reinthaller A, Kainz C. Immunohistochemical and serological evaluation of CD44 splice variants in human ovarian cancer. Br J Cancer. 1995;72:1494-7.

35. Kainz C, Kohlberger P, Tempfer C, Sliutz G, Gitsch G, Reinthaller A, et al. Prognostic value of CD44 splice variants in human stage III cervical cancer. Eur J Cancer. 1995;31A:1706-9.

36. Marhaba R, Bourouba M, Zoller M. CD44v6 promotes proliferation by persisting activation of MAP kinases. Cell Signal. 2005;17:961-73.

37. Jijiwa M, Demir H, Gupta S, Leung C, Joshi K, Orozco N, et al. CD44v6 regulates growth of brain tumor stem cells partially through the AKTmediated pathway. PLoS One. 2011;6, e24217.

38. Nakajima K, Taniguchi K, Mutoh K. Expression of CD44v6 as matrix-associated ectodomain in the bone development. J Vet Med Sci. 2010;72:1017-22.

39. Casali PG, Blay JY, Bertuzzi A, Bielack S, Bjerkehagen B, Bonvalot S, et al. Bone sarcomas. ESMO Clinical Practice Guidelines for diagnosis, treatment and follow-up. Ann Oncol. 2012;Suppl 7:vii100-9.

\section{Submit your next manuscript to BioMed Central and we will help you at every step:}

- We accept pre-submission inquiries

- Our selector tool helps you to find the most relevant journal

- We provide round the clock customer support

- Convenient online submission

- Thorough peer review

- Inclusion in PubMed and all major indexing services

- Maximum visibility for your research

Submit your manuscript at www.biomedcentral.com/submit 